Wilfrid Laurier University

Scholars Commons @ Laurier

\title{
Utilization of global attributions in recognizing and responding to gender discrimination among college women
}

Mindi D. Foster

Wilfrid Laurier University, mfoster@wlu.ca

Follow this and additional works at: https://scholars.wlu.ca/psyc_faculty

Part of the Psychiatry and Psychology Commons, and the Social Psychology Commons

\section{Recommended Citation}

Foster, Mindi D., "Utilization of global attributions in recognizing and responding to gender discrimination among college women" (2000). Psychology Faculty Publications. 40.

https://scholars.wlu.ca/psyc_faculty/40

This Article is brought to you for free and open access by the Psychology at Scholars Commons @ Laurier. It has been accepted for inclusion in Psychology Faculty Publications by an authorized administrator of Scholars Commons@Laurier. For more information, please contact scholarscommons@wlu.ca. 
Running Head: Global attributions for discrimination

Utilization of global attributions in recognizing and responding to gender discrimination

among college women

Mindi D. Foster

Department of Psychology, University of North Dakota

Grand Forks, North Dakota

Correspondence may directed to:

Mindi D. Foster, P.O. Box 8380, Department of Psychology

University of North Dakota, Grand Forks, ND, 58202-8380

Email: foster@badlands.nodak.edu

Fax: 701-777-3454

Abstract

Although learned helplessness theories suggest that global attributions for gender discrimination may serve to promote feelings of helplessness about responding to discrimination, group consciousness theories suggest they may instead be a precursor to enhancing collective actions against discrimination. To examine this theoretical discrepancy, college women completed measures of attributions for gender discrimination, political consciousness (as measured by common fate), participation in collective action, and helplessness behavior among college women. To examine the unique role of global attributions, participants were included if they made external and unstable attributions for discrimination $(\mathrm{N}=231)$. Structural equation modeling showed hat recognizing discrimination occurs globally was associated with an increased sense of common fate, which in turn was related to greater collective action and less helplessness behavior. Theoretical (attributions in an intergroup context) as well as practical (institutional policies on publicizing discrimination) implications were discussed. 
Utilization of global attributions in recognizing and responding to gender discrimination

among college women

Consider this situation: an employer tells his female employee that her productivity has been low and that it is clear she is not attracting new clients to the firm. He says that he is willing to help out if she will see him on a social basis. He further reminds her that if she were performing as she should, there would be no need for this "special attention." She leaves work, remembering similar situations she has experienced. The cat-calls she has received from workers in the street, and harassment by a college professor has left her feeling overwhelmed. She throws her hands in the air in frustration and yells, "It must be me! Nothing every changes --- it's everywhere! I give up --- I can't change anything, I might as well accept it."

This scenario depicts what the reformulated theory of learned helplessness (hereinafter RLH) proposed by Abramson, Seligman \& Teasdale (1978) would suggest should happen when a woman makes internal, stable and global attributions for discrimination. This combination of attributions refers to the belief that the cause of an event is due to oneself versus others, is not likely to change and affects a variety of situations in his/her life, respectively. This attribution style for negative events is thought to be maladaptive in it they will decrease the likelihood of participation instrumental behaviors to change that event (Abramson, et al., 1978). The more internal, stable and global an individual believes a causal explanation to be, the more overwhelmed he/she feels regarding his/her ability to influence this event. As such, the individual will presumably feel ineffective or helpless to alter the situation. Once the individual believes themselves to be helpless to alter a situation, they will exhibit passivity, rather than acting to resolve the situation. For example, the female employee was making an internal attribution, namely that discrimination must be her fault. Further, she made a stable attribution by assuming that the situation will not change. Finally, she made a global attribution in recognizing that such discrimination was impacting various 
aspects of her life. Consequently, she felt helpless to alter such a pervasive problem, reasoning that "I can't change anything." In other words, giving up, or helplessness behavior was her response. Thus, according to the RLH, making internal, stable and global attributions for discrimination may serve to increase an acceptance of discrimination via helplessness behavior rather than taking actions to resolve discrimination.

A more instrumental attribution pattern suggested by RLH is to make external, unstable and specific attributions for why an event has occurred. That is, if an individual believes that the cause of an event is not his/her fault, changeable and limited to a specific situation, then he/she may feel less overwhelmed at the thought of being able to effect changes in that situation. Indeed, the thought of being able to change one situation is less overwhelming than having to change many situations. For example, if the female employee had believed the cause of her employer's treatment was his fault, that such treatment could be changed by changing his behavior and discrimination was only likely to occur in her work life, then she may not feel overwhelmed at the prospect of having to resolve one situation. Consequently, she would presumably be less likely to show helplessness behavior and more likely to participate in behaviors that may effect change. Thus, external, unstable and specific attributions would be considered to decrease helplessness behavior and increase taking collective action to resolve the discrimination.

Much of learned helplessness theory has been applied in an intrapersonal context, namely examining the relationship between a person's attributional style and their psychological (e.g., Abramson, Metalsky \& Alloy, 1989; Amirkhan, 1998; Bruder-Mattson \& Hovanitz, 1990; Peterson \& Seligman, 1984) or physical symptoms (e.g., Peterson \& Seligman, 1987; Peterson, Seligman \& Vaillant, 1988). As such, it is not surprising that external, unstable and specific attributions may have positive consequences while internal, stable and global attributions may have negative outcomes. For example, consider a student who fails an exam and make an internal, stable and global attribution for failing: "I'm stupid, that will never change, I'm 
going to fail my exams in every course." This belief may indeed promote helplessness rather than instrumental behaviors given that these attributions are regarding an individual's behavior. As such, the individual making the attribution has is not likely recognizing that this behavior happens to others. The internal, stable and global attribution style in an intrapersonal context may therefore still involve some degree of isolation, which indeed may promote helplessness behavior.

However, in an intergroup context, what is considered to be an "adaptive" versus "maladaptive" attribution style may change. In particular, global attributions may take on a different meaning in an intergroup context than in an intrapersonal context. In an intergroup context, the global attribution is being made about an intergroup behavior (e.g., "Gender discrimination is happening everywhere".) As such, by definition, there is a group involved who also experience the behavior (i.e., the gender group). Consequently, while such a recognition may indeed be shocking and frustrating, a global attribution for gender discrimination may not involve the same feelings of isolation. Therefore, global attributions in an intergroup context may not be as inhibiting as in an intrapersonal context. Consequently, what has previously been considered an motivational attribution style (external, unstable and specific ) may, in an intergroup context, be less motivational toward resolving situations than external, unstable and global attributions.

In fact, group consciousness theories (Bartky, 1977; Bowles \& Duelli Klein, 1982; Carey, 1980; Dreifus, 1973; Kimmel, 1989; Lerner, 1986; Stanley \& Wise, 1983), which are based in the practical experiences of activists, and have been more recently developed in the context of new social movement theories (Cohen, 1985; Friedman \& McAdam, 1992 ; Gamson, 1992), would suggest that making global attributions for situations of discrimination have an important role to play in promoting collective action. A practical example of the role of external, unstable and global attributions for discrimination can be seen through the feminist consciousness-raising groups of the 1970s (e.g., Carey, 1980; Dreifus, 1973). These groups brought women together to discuss 
their everyday experiences. In doing so, individual women began to realize that their individual experience with discrimination was not isolated. Instead, they heard that discrimination was happening to many other women, in many different facets of their lives (e.g., domestic abuse, harassment at school, on the streets, pay inequity). Such knowledge allowed women to reinterpret their causal explanations for discrimination. By recognizing that discrimination happening to other women, individual women began to realize it was not their fault. Instead, they saw that other women's husbands, employers, friends were a source of discrimination and began to make external attributions for discrimination. As these groups were burgeoning during the civil rights movement, women also began to learn that they could change their situations, realizing that their negative treatment was unstable. Finally, because women began to recognize that discrimination was happening to many women, at all levels of their lives they began to see it as pervasive. In other words, women were encouraged to make external, unstable and global attributions for situations of discrimination.

What differs between RLH and group consciousness theories of motivation is that global attributions were considered to be motivational, in part because they were theorized to enhance the recognition that "the personal is political ." This was a popular slogan in the 1970s aimed at increasing women's political consciousness and action (e.g., Carey, 1980, Dreifus, 1973, Wilkinson \& Schneider, 1990). By recognizing that discrimination was global rather than isolated, women began to realize that if the experience of the group (discrimination) could affect so many people and aspects of life, then ultimately, it could affect individual women as well. In other words, the personal experience of discrimination became viewed as a function of a pervasive political system. A more commonly known psychological conceptualization of this slogan has been referred to by Gurin and Townsend (1986) as a component of a political consciousness, namely common fate.

Common fate similarly refers to the belief that the individual experiences the same fate as the group. Thus, global attributions for discrimination were 
considered to enhance a sense of common fate.

According to group consciousness theories (e.g., Bartky, 1977, Wilkinson \& Schneider, 1990), as a part of a political consciousness this sense of common fate would in turn enhance the likelihood of collective action. In particular, when women consider the group experience to be related to their personal experience, the group becomes personally relevant. As such, behaviors aimed at enhancing group status become more relevant to enhancing one's own status. In addition, if the group is personally relevant, an individual woman may feel less isolated and helpless given this connection with her social group. In contrast, if the effect of the group experience on the individual's experience is not apparent, the group is likely considered to be less personally relevant. Therefore, participation in collective action would be an unlikely response for what may be considered an individual rather than a group problem. Further, if the group is less personally relevant, helplessness behavior may be more likely given an individual may feel more isolated without a connection to her social group.

In summary, while RLH and group consciousness theories would agree on the psycho-social benefits of external and unstable attributions, they differ on their theorized implications for global attributions. Specifically, RLH considers global attributions to be associated with a sense of helplessness, while group consciousness theories suggest that global attributions for gender discrimination play a role in motivating collective actions to enhance group status. In particular, the more global women believe discrimination to be, the more likely they will develop a political consciousness, as conceptualized by common fate. Given their recognition of the personal relevance of the group, they will be more likely to participate in collective action, and less likely to participate in helplessness behaviors. Thus, the present study examined the independent role of global attributions in recognizing a common fate of gender discrimination and behavioral responses to discrimination. 


\section{Participants and Procedure}

Female participants $(\underline{\mathrm{N}}=262$; Mean age $=21$ years $)$ from psychology courses at the University of North Dakota were asked to read and sign a consent form describing their participation in the study. They then completed a 30 minute questionnaire, after which they were given an oral and written debriefing regarding the purpose of the study.

University women were asked to participate in this study as they are group of women who experience a large proportion of discriminatory events, even before they enter the workforce. For example, some researchers (Calhoun \& Atkeson, 1991; Koss, 1992) assert that 1 in 4 college women are likely to experience sexual assault during their college years. Reports on sexual harassment in the academy suggest that between $9 \%$ and $38 \%$ of college women are harassed (Dziech \& Weiner, 1990; Martin, 1995). While discriminatory events indeed occur off campuses, given what appears to be a concentration of these events on campuses, there is a need to understand how these young women respond to discrimination.

\section{$\underline{\text { Materials }}$}

Attributions for Discrimination. In order to assess attributions for discrimination, participants read 6 scenarios that were developed for this study, each depicting a different situation of discrimination (see Appendix). To ensure these scenarios were accurately depicting gender discrimination, they were piloted on a separate sample of 40 women. These participants were asked to read the scenarios and then indicate on a scale ranging from totally disagree (0) to totally agree (10) the extent to which they agreed or disagree that these scenarios exemplified the types of gender discrimination that women encounter. Overall, the women strongly agreed that these scenarios were examples of gender discrimination $(\underline{\mathrm{M}}=8.2)$.

Participants in the present study were asked to read each scenario, and "imagine yourself in each situation. Please try hard to imagine yourself in these situations and then indicate how you would feel if you were in these 
situations by answering the questions below ." They were then asked the extent to which they considered the cause of each situation to be internal/external, stable/unstable and specific/global by indicating on scales ranging from 0 to 10 how much the cause is due to "something about me" to "something about other people/circumstance" (internal/external), how much the cause is "not at all likely to be present again" to "extremely likely to be present" (stable/unstable) and how much the cause influences "just this situation" to "all other areas of my life" (specific/global .) The wording of these questions were derived from the Attribution Style Questionnaire (Peterson, Semmel, von Baeyer, Abramson, Metalsky \& Seligman, 1982). Higher scores reflected more external, stable and global attributions for discrimination.

Common Fate. In order to assess the extent to which women felt a sense of common fate with other women, participants indicated on a scale ranging from disagree totally (0) to agree totally (10), how much they disagreed or agreed with six statements. To remain consistent with Gurin and Townsend's (1986) generalized two-item measure of common fate, two items assessed a general sense of common fate: "The status of women has nothing to do with my own personal status"; "Realizing the kinds of discrimination women face has led me to believe that I too could face discrimination". While these items were based on Gurin and Townsend's (1986) measure, they were reworded, as the original wording which asks about the impact of the women's movement on one's life was suspected to have less relevance to a university sample in the 1990s. Four additional items were developed to assess the impact of more explicit instances of gender discrimination on individual women. The items were based on pilot work conducted to generate a list of discriminatory experiences common among university women (Foster, 1996): “The obstacles that women have to face in the work world will ultimately affect me in my career too"; "The fact that female students have traditionally been treated worse by teachers (especially science teachers) than male students has little to do with how I was treated in school by my teachers"; The fact that the average 
woman gets paid $30 \%$ less than the average male is not likely to have an impact on how much my employers will pay me compared to men"; The media's portrayal of the ideal woman as 'thin, beautiful and sexy' has affected my own image of myself (either to achieve that ideal, or to ignore it)." Some items were recoded such that on all items, high scores reflected high shared experience.

Collective action (Foster \& Matheson, 1995). Collective action is defined as any action aimed at enhancing group status as opposed to individual status (Wright, Taylor \& Moghaddam, 1990). Using a scale ranging from "never participate/engage in" (0) to "always participate/engage in" (10), participants indicated how often they participate in 5 actions: "I volunteer for groups aimed to help women such as shelters for abused women"; "I am a member of an organization that deals with women's issues"; "I organize events that deal with women's issues"; "I participate in fundraisers, consciousness-raising events etc. that attempt to increase the overall status of women"; "I give lectures or talks on women's issues."

Helplessness Behavior (Foster, in press). In order to assess the extent to which participants would engage in helplessness behavior, four items assessed passive/helplessness behaviors with respect to women in particular. Using a scale ranging from "never participate/engage in" (0) to "always participate/engage in" (10), participants responded to "I don't act for women because it doesn't matter"”; "I don't stand up for myself as a woman"; "Even though certain strategies to fight discrimination against women may not work, I don't bother to use new ones"; "I refuse to take action for women on my own ." Originally, these items were derived from Peterson's (1993) helplessness behavior scale and modified to reflect helplessness behavior in regards to enhancing women's status.

\section{Results}

\section{Descriptive Statistics}

To assess the attributions for discrimination, perceived common fate and 
participation in collective action and helplessness behavior, means were calculated. Women tended to make external $(\underline{\mathrm{M}}=7.58, \underline{\mathrm{SD}}=1.62$, Range $=$ 8.27), unstable $(\underline{\mathrm{M}}=7.71, \underline{\mathrm{SD}}=1.44$, Range $=7.91)$ and global attributions for discrimination $(\underline{\mathrm{M}}=6.19, \underline{\mathrm{SD}}=1.93$, Range $=9.55)$. They indicated perceiving common fate with other women $(\underline{\mathrm{M}}=6.6, \underline{\mathrm{SD}}=1.7$, Range $=8.73)$. Consistent with past research (e.g., Foster \& Matheson, 1995; Wright, Taylor $\&$ Moghaddam, 1990), average participation in collective action was low $(\underline{M}=$ $1.54, \underline{\mathrm{SD}}=1.88$, Range $=7.80)$, as was helplessness behavior $(\underline{\mathrm{M}}=1.99, \underline{\mathrm{SD}}=$ 1.74 , Range $=9.25)$.

\section{$\underline{\text { Structural Model }}$}

Because RLH and group consciousness theories agree on the implications of external and unstable attributions, the present study sought to examine the impact of global attributions given women already made external and unstable attributions. Therefore, participants were included in the model if they made external and unstable attributions for discrimination $(\mathrm{N}=231)$. These participants scored above the midpoint on each of the internal/external and stable/unstable measures, indicating they were making external, unstable attributions for discrimination.

Structural equation modeling, which tests hypotheses about patterns of relationships among latent variables, was used to assess the multivariate relationships between global attributions, common fate, collective action and helplessness behavior. Assessment of fit of the measurement models, as well as the structural equation model, was based on several indices. Although the $\chi 2$ statistic tests how well the hypothesized model data fits the observed data, it tends to be over-sensitive to sample size (Bentler \& Bonnet, 1980; Byrne, 1989). Thus, researchers suggest that the $\chi 2$ be reported, but that it not be used as the primary index of goodness of fit (Hoyle \& Panter, 1995; Hu \& Bentler, 1995).

Instead, alternative indices of fit are utilized in structural equation modeling. First, the average off-diagonal residuals were examined, which represent the 
average amount of correlation between the hypothesized and observed data that is unexplained by the model. If residuals are small, the model is considered to exhibit good fit of the data (Hu \& Bentler, 1995). A second criterion is the Comparative Fit Index (CFI; Bentler, 1990) ranges from 0 to 1.00, with .90 indicating adequate fit of the data (Byrne, 1994; Hoyle \& Panter, 1995; Hu \& Bentler, 1995). Finally, the root mean square error of approximation (RMSEA) represents the amount of error in approximating the population data by the sample data. Values of .05 and less are considered to reflect close fit of the data, values between .05 and .08 reflect moderate fit of the data, and values above 1 reflect poor fit of the data (Browne \& Cudeck, 1993; Byrne, 1994; MacCallum, Browne \& Sugawara, 1996). The RMSEA also provides a 90\% confidence interval for the value. While all indices are generally considered, research suggests that when there is a dispute between the indices, the residuals are the most reliable (Byrne, 1991; Hu \& Bentler, 1995). All models (see Table 1) were assessed using EQS, a statistical package designed to test structural models (Bentler \& Wu, 1995). Maximum likelihood estimation was used for all models, and the Satorra-Bentler Scaled Statistic correction was also for the full model, due to small sample size (Bentler, 1995; Byrne, 1994; Hu \& Bentler, 1995).

The first step in testing the model was to ensure that the latent variables were well measured (Byrne, 1989). Thus, confirmatory factor analyses were performed to assess the fit for each latent variable (global attributions, common fate, collective action and helplessness behavior). These measurement models were specified such that each factor could be explained by the indicator variables designed to measure it, and the error terms would be uncorrelated. The one exception was the collective action measurement model, which based on past research (Foster, 1998) was specified with an correlated error term for the items 1,5. As Table 1 indicates, all indices for the measurement models suggested that each of the variables were good estimates of the latent variables they were designed to measure. In particular, the several of X 2 values were non-significant, suggesting no significant differences 
between the observed and hypothesized data. The CFI values ranged between .99 and 1.0, and the residuals were very low, indicating very good fit of the data. Finally, RMSEA values ranged from .00 to .08 indicating moderate to excellent fit of the data for all the latent variables.

Given that the measurement models were stable, a structural model was then specified, hypothesizing that the more women made global attributions for discrimination, the more they would express a sense of common fate. In turn, the more common fate women expressed, the more they would participate in collective action, and less in helplessness. As Table 1 indicates, the CFI for this model was .92, and the residuals were low (.06) indicating good fit of the data. Finally, the RMSEA and its confidence interval also suggest close fit of the data. Thus, the model was considered to accurately describe the data. The final loadings for each factor and path coefficients between the factors are presented in Figure 1.

\section{Discussion}

The present study shows that while the RLH suggests global attributions should enhance helplessness behavior, in an intergroup context, global attributions for gender discrimination may ultimately serve to empower women via an enhanced sense of political consciousness. In support of this, the more women made global attributions for discrimination, the more common fate they reported. This is consistent with group consciousness theories (e.g., Bartky, 1977; Carey, 1980; Lerner, 1983) which suggest that recognizing discrimination is global rather than isolated is a step toward having a political consciousness. These theories describe a political consciousness as viewing the personal as political, or as sense of common fate (Gurin \& Townsend, 1986). If women recognize that discrimination is systemic (i.e., global attribution for discrimination), they come to recognize that given the pervasive impact of "the system", discrimination could ultimately affect them as well. In contrast, if women believe situations of discrimination are isolated to particular areas of their life (i.e., specific attributions for discrimination), they may be less likely to recognize that 
discrimination could affect them personally. They may reason that, unlike global events, isolated events can be easily escaped and therefore, less likely to impact upon them. Thus, global attributions for discrimination may play an important role in developing a political consciousness.

In turn, the recognition that individual women are affected by their group's experience of discrimination appeared to be empowering, in that common fate was positively associated with taking greater collective action and less helplessness behavior. Again consistent with group consciousness theories (e.g., Bowles \& Duelli Klein, 1983), believing that the group impacts upon one's personal life is empowering because it may serve to make collective action more personally relevant. In particular, if a woman recognizes that what happens to the group (discrimination) has also affected her personal life (i.e., common fate) then behaviors aimed at enhancing group status become more relevant to enhancing one's own status. Thus, the belief that the group can affect the individual (common fate) appears to be empowering for these women.

Given the correlational nature of the study however, alternative interpretations of the direction of relationships are possible. For example, women who participate in collective action may develop a greater awareness of how the group affects the individual and therefore learn to make more global attributions. Experimental studies are therefore needed to examine how making a global attribution for a situation of discrimination may affect collective action. In addition, future research will need to examine global attributions for experienced discrimination rather than hypothetical situations. The present study used hypothetical situations to remain consistent with past operational definitions of attributions (Peterson et al., 1982; Whitely, 1991). While studies, including this one, have indeed found relationships between attributions for hypothetical situations and behavior (e.g., Nolen-Hoeksema, Girgus \& Seligman, 1986; Peterson, 1993), examining experienced situations may provide additional information. It may be that the use of hypothetical situations to measure attributions may actually underestimate the relationships 
found in the present study. When people experience discrimination and are faced with its global nature, there may be associated feelings of anger, frustration, and/or resentment. According to relative deprivation theory, negative emotions in response to experienced discrimination have been found to further motivate collective action (e.g., Birt \& Dion, 1987; Runciman, 1966). Thus, emotional reactions to global attributions may further enhance a political consciousness and collective action.

Despite the correlational nature of the study, the role that global attributions appears to play in a political consciousness and indirectly, collective action should not be underestimated. These findings highlight the need to further examine the psycho-social benefits of global attributions in an intergroup context. At first glance, global attributions and common fate are beliefs that appear to elicit frustration, and feelings of being overwhelmed in that they both involve the notion that something pervasive is affecting an individual.

Given the intergroup context however, these beliefs may have psycho-social benefits. On a social level, the present study showed that actions to enhance women's status appear more likely as women's political consciousness increased. On a psychological level, global attributions and a political consciousness may reduce feelings of anxiety regarding discrimination in that there are others who may provide a sense of social support. Future research will need to examine the various ways in which global attributions in an intergroup context may provide such psycho-social benefits.

If as the present study suggests, global attributions provide social benefits, then institutional policies for publicizing information about discrimination may need to be reconsidered. Traditionally, institutions such as universities or corporations, and even the police often withhold information about the incidence of discrimination from the public. There is a tendency for institutions to make any incident of discrimination appear isolated rather than widespread in an attempt to reduce the potential for "public panic." For examples, universities may not make rape incidence statistics available to their students. Many students may therefore believe that rape and harassment is 
isolated to places off- campus. In doing so, the institution may believe it has made it easier for potential victims of discrimination to function on a daily basis without feelings of fear or helplessness. However, as the present study suggests, by encouraging as sense that discrimination is isolated, victims of discrimination may believe they are alone in the experience. Indeed, fear and helplessness may ensue without others on whom to depend. Thus, by implying the discrimination is isolated, institutions may be encouraging the very behavior (helplessness) they seek to prevent. Instead, if institutions disclose their information regarding the risk of discrimination, potential victims may recognize they are not alone, and with the support of their group, may become empowered to enhance the status of that group.

\section{References}

Abramson, L. Y., Seligman, M. E. P., \& Teasdale, J. (1978). Learned helplessness in humans: Critique and reformulation. Journal of Abnormal Psychology, 87, 49-74.

Abramson, L. Y., Metalsky, G. I., \& Alloy, L. B. (1989). Hopelessness depression: A theory-based subtype of depression. Psychological Review, 96 , 358-372.

Amirkhan, J. H. (1998). Attributions as predictors of coping and distress. Personality and Social Psychology_Bulletin, 24, 1006-1018.

Bartky, S. L. (1977) Toward a phenomenology of feminist consciousness. In M. Vetterling-Braggin, F. Elliston, \& J. English (Eds.), Feminism and philosophy (pp. 22-37). Totawa, NJ: Littlefield.

Bentler, P. M. (1990). Comparative fit indices in structural models. Psychological Bulletin, 107, 238-246.

Bentler, P. M. \& Bonnett, D. G. (1980). Significance tests and goodness-offit in the analysis of covariances structures. Psychological Bulletin, $\underline{88}, 588-$ 606.

Birt, C. M. \& Dion, K. L. (1987). Relative deprivation theory and responses 
to discrimination in a gay male and lesbian sample. British Journal of Social Psychology,_26, 139-145.

Bowles, G. \& Duelli Klein, R. (1983). Theories of women's studies . London: Routledge.

Browne, M. W., \& Cudeck, R. (1993). Alternative ways of assessing model fit. In K. A. Bollen \& J. S. Long (Eds.), Testing structural equation models (pp. 136-162). Newbury Park, CA: Sage.

Bruder-Mattson, S. F., \& Hovanitz, C. A. (1990). Coping and attributional

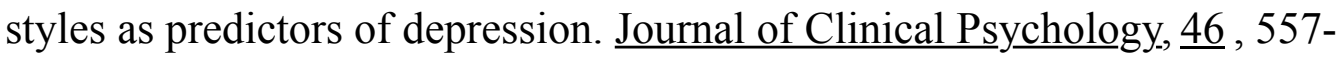
565.

Byrne, B. M. (1994). Testing for the factorial validity, replication, and invariance of a measuring instrument: A paradigmatic application based on the Maslach Burnout Inventory. Multivariate Behavioral Research, $\underline{29}$ (3), 289311.

Byrne, B. M. (1989). A primer of LISREL: Basic applications and programming for confirmatory factor analytic models. New York: SpringerVerlag.

Cohen, J. L. (1985). Strategy or identity: New theoretical paradigms and contemporary social movements. $\underline{\text { Social Research, }}$ 52, 663-716.

Carey, P. (1980). Personal is political. Canadian Women's Studies, $\underline{2}$, 4-7.

Driefus, C. (1973). Women's fate: Rap from a feminist consciousnessraising.group. New York: Bantam.

Calhoun, K. S., \& Atkeson, B. M (1991). Treatment of rape victims: Facilitating_psychosocial adjustment. Elmsford, NY: Pergamon Press.

Dziech, B. W., \& Weiner, L. (1984). The lecherous professor: Sexual harassment on campus ( 2 nd ed.). Urbana: University of Illinois Press.

Foster, M. D. (1998, May). Avoidance coping with personal discrimination: Action or inhibition. Poster presented at the American Psychological Society 
Annual Conference, Washington DC.

Foster, M. D. (in press). Positive and negative responses to personal discrimination: Does coping make a difference? Journal of Social Psychology.

Foster, M. D. (1996). The socio-cognitive factors in reducing the personal/group discrimination discrepancy. Unpublished doctoral dissertation. Carleton University, Ottawa, Canada.

Foster, M. D. \& Matheson, K. (1995). Double relative deprivation: Combining the personal and political. Personality and Social Psychology Bulletin, 21, 1167-1177.

Friedman, D. \& McAdam, D. (1992). Networks, choices and the life of a social movement. In A. D. Morris \& C. McClurg Mueller (Eds.),. Frontiers in Social Movement Theory. (pp.156-173). New Haven: Yale University Press.

Gamson, W. A. (1992). The social psychology of collective action. In A. D. Morris \& C. McClurg Mueller (Eds.),. Frontiers in Social Movement Theory (pp. 53-76). New Haven: Yale University Press.

Gurin, P., \& Townsend, A. (1986). Properties of gender identity and their implications for gender consciousness. British Journal of Social Psychology, $\underline{25}, 139-148$.

Hoyle, R. H. \& Panter, A. T. (1995). Writing about structural equation

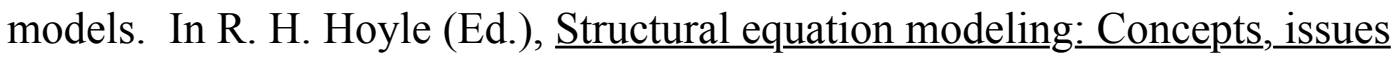
and applications (pp. 158-176). Structural equation modeling: Concepts, issues and applications (pp. 76-99). Thousand Oaks, CA: Sage.

Kimmel, E. B. (1989). The experience of feminism. Psychology of Women Quarterly, 13, 168-186.

Koss, M. P. (1992, Spring). Rape on campus: Facts and measures. Planning for Higher Education, 20, 21-28.

Lerner, G. (1986). The creation of patriarchy. New York: Oxford 
University Press.

MacCallum, R. B., Browne, M. W., \& Sugawara, H. M. (1996). Power analysis and determination of sample size for covariance structure modeling. Psychological Methods, 1 (2), 130-149.

Martin, S. E., (1995). Sexual harassment: The link joining gender stratification, sexuality and women's economic status. In J. Freeman (Ed.), Women: A feminist perspective (5 th ed., pp-22-46). Mountain View, CA: Mayfield.

Nolen-Hoeksema, S., Girgus, J. S., \& Seligman, M. E. P. (1986). Learned helplessness in children: A longitudinal study of depression, achievement and explanatory style. Journal of Personality and Social Psychology, , $\underline{51}$, 435442.

Peterson, C. (1993). Helplessness behavior. Behaviour Research and Therapy,31 (3), 289-295.

Peterson, C. \& Seligman, M. E. P. (1984). Causal explanations as a risk factor for depression: Theory and evidence. Psychological Review , 91, 347374.

Peterson, C. \& Seligman, M. E. P. (1987). Explanatory style and illness. Journal of Personality, $\underline{55}, 237-265$.

Peterson, C. , Seligman, M. E. P., \& Vaillant, G. E. (1988). Pessimistic explanatory style is a risk factor for physical illness: A thirty-five year longitudinal study. Journal of Personality and Social Psychology, 프, 23-27.

Peterson, C., Semmel, A., von Baeyer, C., Abramson, L. Y., Metalsky, G.I., $\&$ Seligman, M. E. P. (1982). The attributional style questionnaire. Cognitive Therapy and Research, $\underline{6}, 287-299$.

Runciman, W. G. (1966). Relative deprivation and social justice: A study of attitudes to social inequality in twentieth century England . Berkeley, CA: University of California Press. 
Stanley, L. \& Wise, S. (1983). Breaking out: feminist consciousness and

feminist research. London: Routledge \& Kegan Paul.

Whitley, B. E., Jr. (1991). A short form of the Expanded Attributional Style

Questionnaire. Journal of Personality Assessment, $\underline{56}$, 365-369.

Wilkinson, N. \& Schneider, M. (1990). The development of a feminist

consciousness in women: work in progress. Paper presented at the Canadian

Psychological Association Annual Conference, Ottawa, Ontario.

Wright, S. C., Taylor, D. M., \& Moghaddam, F. M. (1990). Responding to membership in a disadvantaged group: From acceptance to collective protest. Journal of Personality and Social Psychology, , 58, 994-1003.

Table 1

$\underline{\text { Summary of Test Statistics for Measurement and Full Structural Model }}$

Measurement Models

(Confirmatory Factor Analyses).

$\underline{\mathrm{X}} \underline{2}$ df residuals $\mathrm{CFI}$ RMSEA $\underline{\mathrm{CI}}$

$\begin{array}{llllllll}\text { Global attributions } & 14.07 & 9 & .02 & .98 & .08 & .04-.11\end{array}$

$\begin{array}{llllll}\text { Common Fate } & 4.48 \mathrm{a} 9 & .02 & 1.0 & .00 & .00-.04\end{array}$

$\begin{array}{llllll}\text { Collective Action } & 7.24 \mathrm{a} 4 & .02 & .99 & .06 & .00-.13\end{array}$

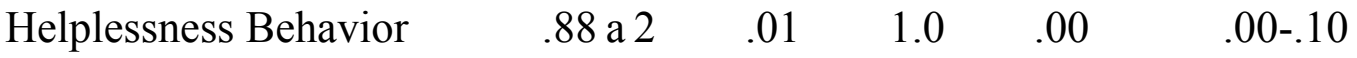

$\begin{array}{lllllll}\text { Full Model } & 299.63 & 185 & .06 & .92 & .05 & \end{array}$

Note: a refers to a X $2>.05$, indicating that there are no significant differences between the hypothesized and observed data.

CFI refers to Comparative Fit Index, RMSEA refers to the Root means square error of approximation, CI refers to the confidence interval associated with RMSEA.

Appendix

Scenario 1:

Suppose you are out jogging, and you pass a large group of guys. They start yelling and whistling at you: "Hey baby--looking good--why don't bring that over here baby."

Scenario 2:

Imagine you just completed graduate school--6 long years of studying and researching! You have finally earned the title "Dr." and you are very proud of yourself. During the term however your students refer to you as "Miss", and refer 
to your male colleagues as "Dr.

Scenario 3:

You bring your car in to the garage to be fixed. You're not very confident about your car knowledge, but you've just completed a beginner's course on how to better understand your car. You tell the mechanic you believe the problem is a loose fan belt, but you can't be sure. He responds "Don't worry honey, we know more about this stuff--we'll do the diagnosing."

Scenario 4:

Suppose again you are out jogging, and you pass a large group of guys. They start yelling and whistling at you: "Hey baby--looking good--why don't bring that over here baby". But you ignore them, and cross to the other side of the street. Seeing your lack of interest they yell "Bitch!"

\section{Scenario 5:}

You just got a job at a very popular new restaurant, which is great because you could really use the money that good tips can bring in. A friend says to you, "You know, you have great legs--if you show them off, you could get better tips."

Situation 6:

As a part of a demonstration in one of your classes, the whole class is asked to complete a short task assessing your cognitive ability. The professor warns the class that the women should try extra hard because this particular measure has been known to yield low scores for women, while men end up always performing well. The professor grades the tasks after everyone has completed it and says, "The men performed well, the women did not."

\section{Figure Caption}

Figure I. Final model of the relationships between global attributions, common fate, collective action and helplessness behavior. 